\title{
Deviated nose: Physiological and pathological changes of the nasal cavity
}

\author{
Taek Kyun Kim, Jae Yong Jeong \\ THE PLUS Plastic Surgery, Seoul, Korea
}

Deviated nose is highly challenging in rhinoplasty since the surgeon should consider both aesthetic and functional aspects of the nose. Deviated nose correction is surgically complex, and a thorough understanding of the mechanical and physiological changes of intranasal structures, including the septum and turbinates, is necessary for functional improvement.

Keywords Deviated nose / Nasal physiology / Septoplasty / Turbinoplasty

\author{
Correspondence: Jae Yong Jeong \\ THE PLUS Plastic Surgery, \\ 9 Garosu-gil, Gangnam-gu, \\ Seoul 06035, Korea \\ Tel: +82-2-6933-7587 \\ Fax: +82-2-6933-7588 \\ E-mail: dogearjeong@naver.com
}

This review article was prepared by the Korean Academic Association of Rhinoplasty Surgeons (KAARS).

We would like to express special thanks to Dr. Hoon Young Lee for English correction of this manuscript.

\section{INTRODUCTION}

Correction of a deviated septum is often necessary in cases of deviated nose because those two conditions frequently occur together. Additionally, surgeons must have a clear understanding of septal management because septal deviation may be observed in patients who do not exhibit external deviation. In deviated nose correction, both aesthetic and functional aspects should be considered [1].

Nasal obstructive symptoms may occur with even a small alteration of vestibular airflow direction since a slight manipulation of nasal structures during surgery may result in significant changes in nasal physiology. With the increasing frequency of cosmetic open rhinoplasty with septal management, the number of patients who complain of postoperative functional problems has also increased. Surgeons must have an in-depth under- standing of postoperative physiological changes in patients with deviated nose.

The nose plays a role as an airway with other functions, including air conditioning and air cleaning. It also plays a profound role in phonation and olfaction, as well as functioning as a reflex and secondary sex organ (as the vomeronasal organ may be related to pheromones) [2]. The functional role of the nose as an airway is important because nasal structures contribute to $30 \%$ $50 \%$ of the overall resistance of inspired air [3]. As mentioned previously, mechanical changes of internal nasal structures, including the septum, affect overall nasal function.

This article mainly describes the physiological changes of intranasal structures in nasal deviation. Moreover, the surgical management of patients with deviated nose and possible complications during septoplasty and turbinoplasty will be explained afterwards. 


\section{MECHANICAL CHANGES IN DEVIATED NOSE}

\section{Structural changes in the nasal cavity}

The cartilaginous septum is a somewhat rigid, but flexible structure comprised of hyaline cartilage situated between the septal lining, which includes the mucosa, and perichondrium. Its tensile properties allow it to withstand external forces to a certain extent. However, these properties also make it susceptible to deviation or deformation resulting from posttraumatic stress or postoperative injury including hematoma. Exposure of the cartilaginous septum to mechanical stimuli such as trauma or surgery, especially during the growth period, may initiate excessive growth or tension accompanied by scar formation, affecting the development, vector, and shape of septal cartilage, thus explaining the etiology of septal deviation [4-6].

Chondrocytes and the extracellular matrix are the two structural components of cartilage, which does not have an intrinsic blood supply; therefore, its viability is dependent upon the diffusion of oxygen and nutrients through the extracellular matrix, which is regulated by chondrocytes [7].

Cartilage autografts tend to undergo resorption to some extent as time passes. Clinically, this type of cellular death, or apoptosis, leads to graft loss (total or partial) and is related to degradation of the matrix in cartilage. With no means of expelling dead cells through macrophages, the apoptotic remnants of cellular degradation in cartilage may cause additional damage to the cartilage, impacting subsequent reparative processes. Furthermore, because cartilage has no reparative potential due to its lack of mesenchymal stem cells, mechanical trauma may lead to cartilage injury and initiation of the degradation process. Therefore, it is important to note that more volume loss may take place in a cartilage graft harvested from a traumatized septum than in a graft sourced from non-traumatized cartilage [8].

The nasal swell body, also referred to as Kiesselbach's ridge, septal erectile body, septal intumescence, septal cavernous body, anterior septum tuberculum, or septal turbinate, is shown as a thickening of the mucosa, bone, and/or cartilage on computed tomography (CT) images (Fig. 1). The septal swell body is located under the nasal bones, superior to the inferior turbinates, and anterior to the middle turbinates. The nasal septal body may show less capacity for vasoreactivity than the inferior turbinate mucosa since the swell body contains abundant mucous glands without true cavernous tissue. Although relatively little information has been published on the nasal swell body, it is found near or in a crucial region of the physiological flow-limiting segment of the nasal cavity and its contribution to the nasal valve area warrants additional research [9].

In cases of compensatory inferior turbinate hypertrophy secondary to deviation of the septum, bone is the primary cause of inferior turbinate expansion, whereas the medial mucosa, which is the major contributor to bilateral inferior turbinate hypertro-

\section{Fig. 1. Septal swell body (asterisk) on CT scan}

(A) Axial view, (B) coronal view corresponding to level 1 on the axial view, (C) coronal view corresponding to level 2 on the axial view. CT, computed tomography.
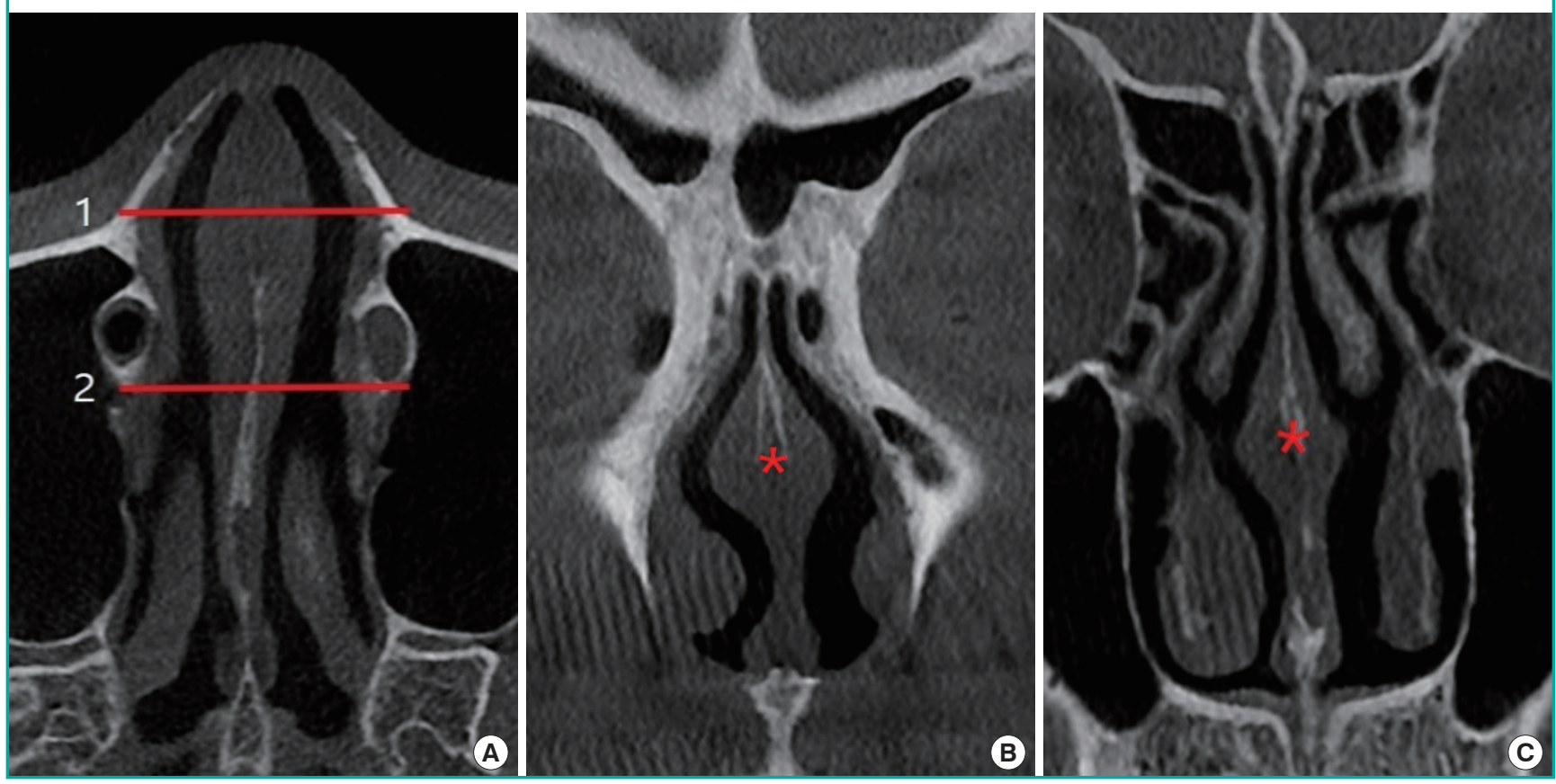


\section{Fig. 2. Hypertrophy of inferior turbinate on CT scan}

Compensatory bony hypertrophy (asterisk) of the inferior turbinate on computed tomography (CT) secondary to septal deviation.

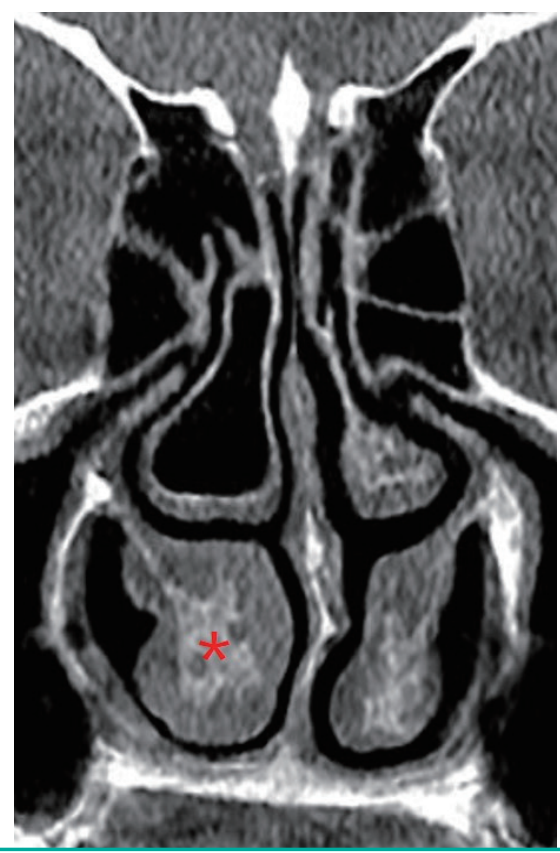

phy, does not make a significant contribution (Fig. 2) [10]. A histological study of inferior turbinates from patients with septal deviation and compensatory hypertrophy demonstrated significant bony expansion compared with control cadavers. Specifically, the bony thickness of the inferior turbinate was twice as high as in controls, and bony hypertrophy accounted for threefourths of inferior turbinate growth [11].

Researchers have suggested that unilateral turbinate expansion protects the nasal passage from drying and crusting resulting from excess airflow, but the underlying mechanism has yet to be elucidated $[11,12]$. Dynamic enlargement of the inferior turbinate can be caused by vascular engorgement as part of the nasal congestion-decongestion cycle. In coronal CT scans in patients with compensatory hypertrophy of the inferior turbinate, the bony and mucosal parts both showed larger cross-sectional areas. Lateralization of the inferior turbinate, including its bony and mucosal parts, using an in-out fracture is performed for compensatory hypertrophy (Fig. 3) [13].

\section{Changes in airway resistance}

The primary function of the nose is to provide a conduit for the passage of external air into the pulmonary system for blood oxygenation. Despite its relatively short length compared to the rest of the airway, roughly half of the total airway resistance occurs in the nose [14]. This fact can be explained through the laws of physics, since changes in the pressure, volume, and width of the
Fig. 3. Management of compensatory hypertrophy of inferior turbinate

(A) The enlarged bony part of inferior turbinate on a preoperative computed tomography (CT) scan, (B) the result of lateralization of the inferior turbinate, including the bony part, using an in-out fracture (the author's method) on a postoperative CT scan.
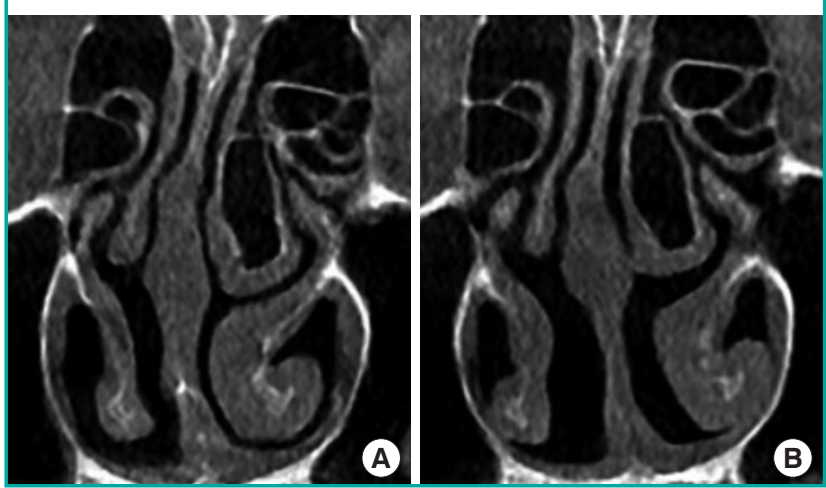

airway significantly influence airflow.

Flow is directly proportional to the difference in pressure and inversely proportional to the resistance (Ohm's law: flow $=\mathrm{dP}$ / resistance). Air flows through the nose in the presence of a pressure difference between the external nares and the nasopharynx. Decreased airflow is caused by structural limitations resulting from intraluminal masses, valve incompetence, septal deflection, or hypertrophy of the turbinates. The total flow at each end of a tube must be equal. Through Bernoulli's principle, it can be shown that if the two ends of a tube have different diameters, the velocity of flow will be different. Clinically, this is seen in incompetent internal or external nasal valves, which form the bottleneck of the airway. The flow velocity can be quantified using Poiseuille's law $\left(\right.$ flow $=$ constant $(\mathrm{K}) \cdot \mathrm{dP} \cdot \mathrm{r}^{4} /$ length $)$. Specifically, Poiseuille's law states that flow is inversely proportional to the length of the tube and directly proportional to the radius raised to the fourth power multiplied by the difference in pressure. As a result, a significant increase in flow can be obtained by even slightly increasing the radius of the tube [15]. From a clinical standpoint, the radius is narrowest at the internal valve, wider at the turbinates, and widest at the posterior choanae. Therefore, obstruction of septal or turbinate origin is common, while obstruction at the posterior choanae rarely occurs [2].

\section{PHYSIOLOGICAL AND MUCOSAL CHANGES}

The mucosa of the respiratory system consists of ciliated pseudostratified columnar epithelium with hair cells, along with basal, strial, and muciparous cells. The ciliated pseudostratified columnar epithelial mucosa lining the nasal area and paranasal si- 


\section{Fig. 4. Histological findings}

A section of nasal mucosa at the level, shown in the illustration, represents the different kinds of epithelium. (A) Histological findings showing the transitional area of the mucosal epithelium ( $\left.H \& E_{1} \times 10\right) ; 1$ is magnified as (B) and 2 is magnified as (C). (B) Pseudostratified columnar epithelium $\left(H \& E_{1} \times 200\right)$ and $(C)$ stratified squamous epithelium $\left(H \& E_{1} \times 200\right)$.
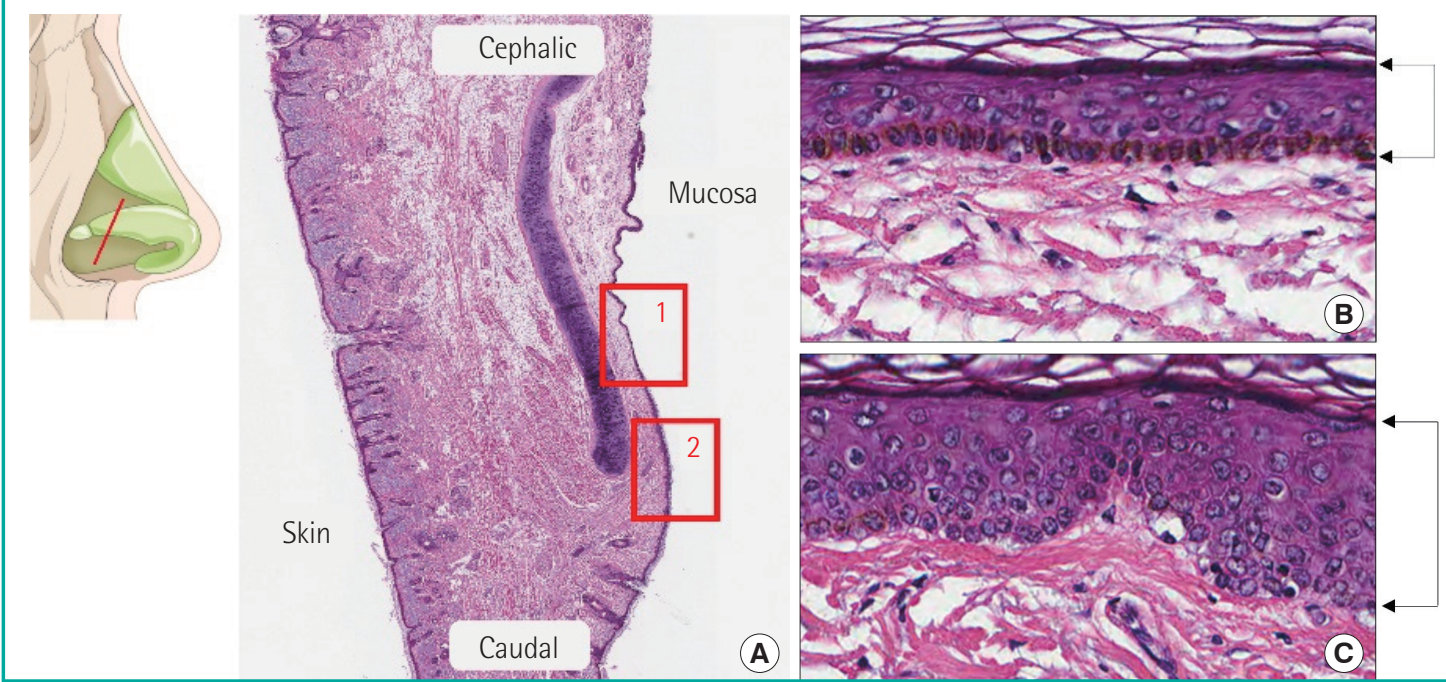

Pseudostratified columnar epithelium

Stratified squamous epithelium

nuses is a continuation of the squamous epithelium of the anterior nasal cavity and pharynx, respectively (Fig. 4) [16].

\section{Septal mucosa}

The septal mucosa is composed of the epithelium, which is made up of ciliated pseudostratified columnar epithelial cells, the basement membrane, and lamina propria. Histopathological changes of the nasal mucosa such as lymphocytic infiltration and squamous metaplasia may be seen when airflow dynamics are altered in the deviated nasal septum. The severity of the changes is more apparent on the concave side of the nasal cavity. Reports have shown more prolonged saccharin clearance time and more severe loss of cilia on the concave side than the convex side. More intense infiltration of inflammatory cells was observed on the concave side, with less dense distribution of serous and mucinous glands on histology [17]. Other studies have also shown changes to both sides of the nasal mucosa, with more severe changes on the concave side $[18,19]$.

In the author's experience, the convex side of the deviated septum shows mucosal thinning due to mechanical pressure of the crooked cartilage, or spurred bone. Therefore, an especially cautious approach is required when elevating the mucoperichondrium on the convex side of the septum (Fig. 5).

Intact ciliary function and adequate production of mucus by goblet cells of the superficial and glandular epithelium in the lamina propria of the nasal mucosa allow adequate mucociliary clearance. Mucus has specific chemical and physical properties that maintain physiological homeostasis in the nasal environ-

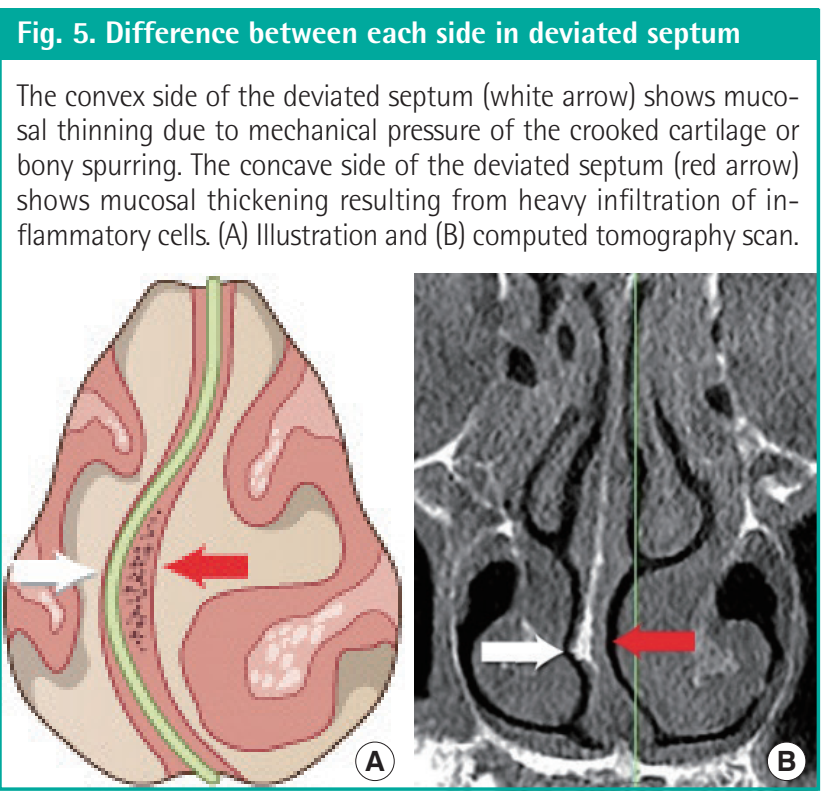

ment. When this environment is disrupted, rhinitis, sinusitis, and other respiratory and pulmonary diseases may occur $[20,21]$.

\section{Turbinate mucosa}

The turbinates, which are bony structures along the nasal walls, are lined with mucosa made up of ciliated pseudostratified columnar epithelium supported by the submucosal lamina propria. The submucosal lamina propria, which contains copious vascular tissue, parasympathetic nerve fibers, goblet cells, and mucous glands, plays a significant role in directing nasal airflow, humidi- 


\section{Fig. 6. Histological findings}

A section of a normal inferior turbinate, showing the difference in thickness of the mucosal layers. $(A)$ Masson trichrome stain $(\times 15)$ and (B) H\&E stain ( $\times 15)$. M, medial mucosa; L, lateral mucosa; I, inferior mucosa; $B$, bone; $V S$, venous sinusoid; $G$, gland.
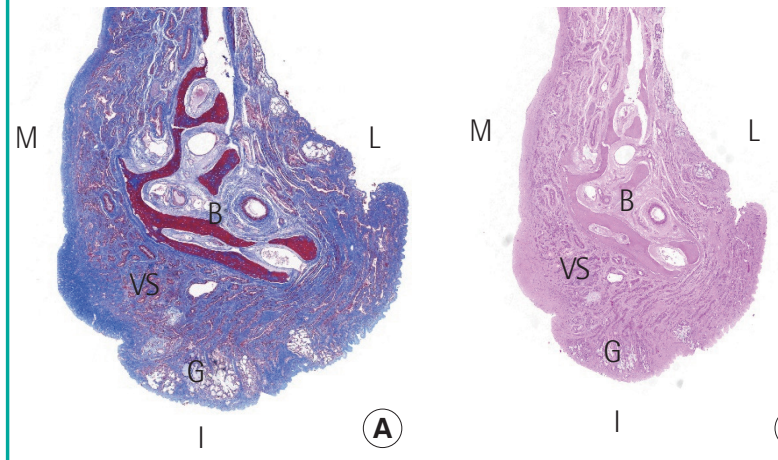

(B)

fication, filtration, and temperature control of inspired air [22].

The blood volume of the sinusoids changes in response to chemical, psychological, thermal, mechanical, and neural stimuli via muscular contraction and relaxation of the artery, which occludes and opens the anastomosis, allowing the venous sinusoids to empty and fill. This volume change alters the speed and volume of airflow by regulating the diameter of the nasal air passage. The inferior turbinate shows this mechanism more prominently than the middle turbinate. Significant hypertrophy, accompanied by the infiltration of eosinophils, neutrophils, lymphocytes, and plasma cells into the lamina propria occurs due to the inflammatory reaction in patients with chronic rhinitis. A prior study found that hypertrophic mucosa had similar proportions of arteries, connective tissue, and submucosal glands to non-hypertrophic mucosa, but the proportion of venous sinusoids was significantly higher. Although the hypertrophic inferior turbinates showed evidence of venous sinusoid engorgement, inflammation, and fibrosis, no evidence of tissue destruction was noted $[23,24]$.

The medio-inferior mucosa of the inferior turbinate has a significant influence on nasal obstruction since it is the thickest, with relatively scarce glandular tissue and an abundance of venous sinusoids. The lateral mucosa, which is relatively thin and rich in glandular components, is important for humidifying inspired air and maintaining the function of the mucociliary clearance system (Fig. 6). Extra precautions are required to preserve the glandular structure during management of the inferior turbinate in older patients because they have diminished glandular components [25]. Vasoreactive engorgement and mucosal inflammation occur in response to allergic stimulation, and immunoglobulin E-mediated activity and eosinophilia are frequently seen in the mucosal epithelium of the inferior turbinate [26].

\section{Fig. 7. Nasal cycle shown on CT scan}

Different features of the turbinate mucosa can be seen in $(A)$ and (B), taken from the same patient on different days before rhinoplasty. CT, computed tomography.
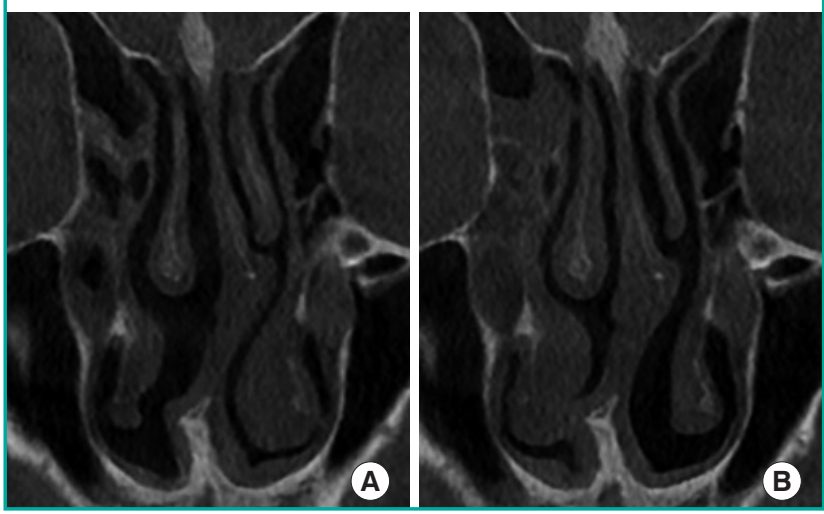

\section{Nasal cycle and paradoxical obstruction}

The periodic congestion and decongestion of sinusoids in the nasal mucosa is responsible for the physiological nasal cycle, which may cause nasal obstruction to occur. The hypothalamus is the central regulator of the nasal cycle, as it regulates the vasoconstriction of the turbinate mucosa [27]. The physiological nasal cycle is affected by humidity, temperature, and the patient's condition. It has been reported to range from 25 minutes to 4 hours, and involves repetitive congestion and decongestion of the nasal mucosa (Fig. 7) [28]. One side becomes congested and resistance increases, causing decreased airflow, but the other side becomes decongested and resistance decreases, causing increased airflow. Healthy people usually do not recognize their nasal cycle, but patients with structural problems, such as a deviated septum, are vulnerable to nasal obstruction during the nasal cycle.

Objective findings are not always correlated to subjective symptoms. Most patients with septal deviation complain of nasal obstruction on the obstructed side (i.e., the convex side of the septum), but ironically, some patients complain of obstruction on the open side (concave side), even with atrophic rhinitis after excessive turbinectomy. It may be challenging to quantify the perceived sensation of nasal obstruction unless it is nearly complete. A prior study using rhinomanometry found that objective and subjective evaluations of nasal airway resistance were negatively correlated in $17.7 \%$ of patients [29]. "Paradoxical nasal obstruction" has been described by Kern and Arbour [30] as a condition where the patient is oblivious to complete uninasal airway obstruction, but complains of intermittent congestion on the concave side. They attribute this perceived sense of obstruction to the occurrence of less mucosal change on the convex side during the nasal cycle. Because of fluctuations in airflow 
and resistance to the perpetuation of the nasal cycle on the concave side, patients may recognize airflow mainly on the concave side. Therefore, during the decongested phase of the nasal cycle on the concave side, airflow and resistance are within the normal range, but during the congested phase, the airflow is diminished and uninasal resistance increases [31].

\section{THE INFERIOR TURBINATE}

The inferior turbinate manages airflow direction and provides the primary resistance to inspired air in the nasal cavity compared to the other two turbinates (superior and middle). The extremely dynamic head of the inferior turbinate, with a height of $14 \mathrm{~mm}$, is located in the internal valve area, which is the flowlimiting segment of the nasal airway [5]. The mucosal part of the inferior turbinate functions as a dynamic organ, containing vascular channels and smooth muscles, while the bony part of the inferior turbinate serves as a rough surface where soft tissue can tightly adhere [32]. The lateral nasal artery and anterior ethmoid artery supply the anterior portion of the inferior turbinate, while the sphenopalatine artery supplies the posterior portion of the inferior turbinate [33].

Airflow passing the nasal valve is directed toward the surface of the inferior turbinate. The resistance of laminar flow passing over the turbinate causes production of mucus, and subsequent humidification. Normally, the level of humidity of inspired air can rise to nearly $100 \%$ at the nasopharynx from zero externally. This explains the significant symptoms of dryness that frequently occur in patients who undergo total turbinectomy [32].
The basement layer separates the epithelium of the inferior turbinate from the lamina propria. In the medial mucosa, the lamina propria is thicker than in the lateral mucosa, extending to the periosteum. The connective tissue of the lamina propria is made up of lymphocytes, other immunocompetent cells, seromucous glands, and an abundant network of thin-walled venous sinuses with a few arteries. The osseous layer of turbinates is made up of cancellous bone (Fig. 6) [25].

Turbinoplasty of the inferior turbinate may make respiration easier by widening the nasal airway. By decreasing the volume of the anterior and inferior portions of the inferior turbinate, the air resistance of the nasal cavity is reduced, consequently improving airflow. Even a minute change in the inferior turbinate volume or position can considerably improve airway passage. Total turbinectomy, lateralization, electrocautery or radiofrequency ablation, cryosurgery, submucosal resection, micro-fragmentation, and resection using a microdebrider are among the surgical techniques used for inferior turbinoplasty. In the past, more aggressive techniques such as total turbinectomy or radical turbinectomy were used. However, these procedures were associated with excessive bleeding, delayed recovery, atrophic rhinitis, and even empty nose syndrome. Consequently, more conservative surgical approaches sparing the nasal mucosa have been recently embraced [5].

An in-out fracture technique, lateralizing the bony part of the inferior turbinate, with additional submucous electrocautery is preferred by the author to correct nasal obstructive symptoms in cases of cosmetic rhinoplasty with turbinate hypertrophy (Fig. 8).

\section{Fig. 8. Inferior turbinate and airway on CT scan}

An objective comparison can be made by measuring the cross-section on a computed tomography (CT) scan before and after turbinoplasty using lateralization of the inferior turbinate with an in-out fracture and additional submucous electrocautery, which is the author's preferred method. (A) Preoperative measured area of the inferior turbinate $\left(159.80 \mathrm{~mm}^{2}\right.$ on the right, $84.47 \mathrm{~mm}^{2}$ on the left), (B) postoperative measured area of the inferior turbinate ( $97.82 \mathrm{~mm}^{2}$ on the right, $81.81 \mathrm{~mm}^{2}$ on the left), (C) preoperative measured area of the medial airway (29.35 $\mathrm{mm}^{2}$ on the right), (D) postoperative measured area of the medial airway (91.23 $\mathrm{mm}^{2}$ on the right).
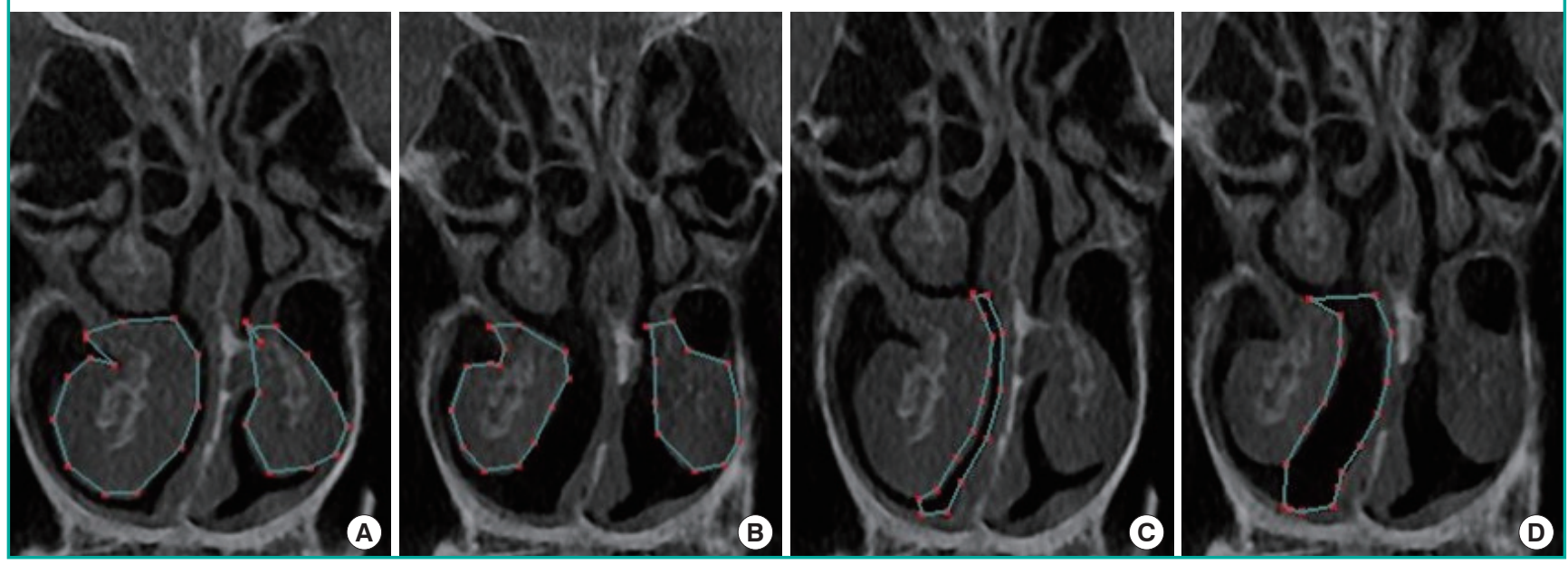


\section{THE MIDDLE TURBINATE}

The roles of the middle turbinate include moisturization of inspired air, lamination of airflow, and deflection of the inspired airflow superiorly, toward the olfactory epithelium. Furthermore, it serves as a drainage area for the frontal and maxillary sinuses, as well as the anterior ethmoidal cells. The middle turbinate shows a denser area fraction of submucosal glands than the inferior turbinate. In contrast, the area fraction of veins is less in the middle turbinate than in the inferior turbinate. These compositional differences reflect the differences in the structures' physiological roles and their contributions to mucus production $[23,34]$.

Concha bullosa, or pneumatized middle turbinate, occurs in approximately $25 \%$ of the population and is a frequently observed anatomical variation of the middle meatus and nasal airway. Although usually asymptomatic, a large concha bullosa can cause symptoms such as nasal obstruction and sinusitis. A unilateral concha bullosa is commonly associated with deviation of the septum to the contralateral side because the pneumatized middle turbinate pushes the septum across the midline during its development. Eighty percent of patients with a large unilateral concha bullosa present with associated septal deviation (Fig. 9) [35]. Although there is no definitive surgical technique to correct concha bullosa, many surgical methods have been described in the literature, of which lateral laminectomy of the middle turbinate is the most prevalently used technique [36].

\section{Fig. 9. A concha bullosa on CT scan}

An incidental finding of concha bullosa on computed tomography (CT), showing a pneumatized middle turbinate (asterisk) with no nasal symptoms.

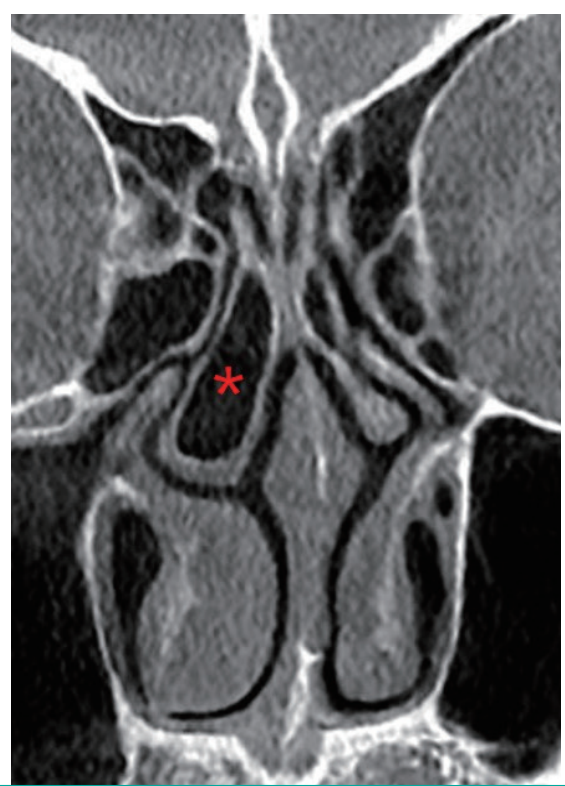

\section{COMPLICATIONS ASSOCIATED WITH AIRWAY MANAGEMENT}

\section{Bleeding}

The vasculature of the nasal septum comprises the sphenopalatine artery, anterior and posterior ethmoid arteries, anterior contributions of the superior labial artery, and posterior contributions of the greater palatine artery [37]. A large arterial arcade of large, thin-walled vessels that make up a consistent anastomotic triangle predominates in the anterior septum, coursing upward and then back down toward the nostril. At Kiesselbach's plexus, also known as Little's area, the terminal branches of vessels gather at the anterior part of the nasal septum. This area is the most common site of bleeding in the anterior septal portion, accounting for $90 \%$ of nasal bleeds, and is frequently observed in young patients. Eschars and crusts can be seen at frequent bleeding sites under endoscopy [38].

Structural problems such as septal spurs or septal deviation may contribute to epistaxis during surgery. Injury to the arterial branch of the greater palatine artery due to excessive resection of the vomer or crest may cause uncontrollable bleeding. The sphenopalatine artery supplies the lateral nasal walls posteriorly, and the anterior and posterior ethmoid arteries supply the lateral nasal wall anteriorly. The main descending branch of the sphenopalatine artery courses from above, $1-1.5 \mathrm{~cm}$ from the posterior border, and branches as it passes forward within the turbinate (Fig. 10) [39].

\section{Synechia}

Synechia, or intranasal adhesion, occurs in 5.9\% to 36\% of patients after septoplasty and turbinoplasty [40-42]. A patient with intranasal synechia may present with nasal obstruction, and a postoperative examination using a nasal speculum and endoscopy is recommended. Preventative measures including silastic sheets, a Doyle splint, and Merocele are recommended based on the findings of a precise postoperative evaluation (Fig. 11).

\section{Septal perforation}

It is generally recommended that the mucoperichondrium be preserved in rhinoplasty. During septoplasty in the correction of deviated nose, however, bilateral submucoperichondrial wide elevation is sometimes inevitable. During submucoperichondrial dissection on the convex side of the deviated septum, cautious dissection is advised because the mucosa can be easily torn, especially near the transitional area to the vomer or in the presence of a septal spur. Because the septal mucoperichondrium is a composite layer of mucosa and perichondrium, improper dissection is a frequent technical error made by surgeons during 


\section{Fig. 10. Blood supply of the nasal cavity}

(A) Lateral wall: the blood supply comes posteriorly from the sphenopalatine artery and superiorly from the anterior and posterior ethmoid arteries. (B) Septal wall: the blood supply along the nasal septum comes from the sphenopalatine artery, as well as the anterior and posterior ethmoid arteries, with contributions from the superior labial artery anteriorly and the greater palatine artery more posteriorly. Kiesselbach's plexus (blue circle) refers to a gathering of terminal branches of vessels at the anterior portion of the nasal septum.
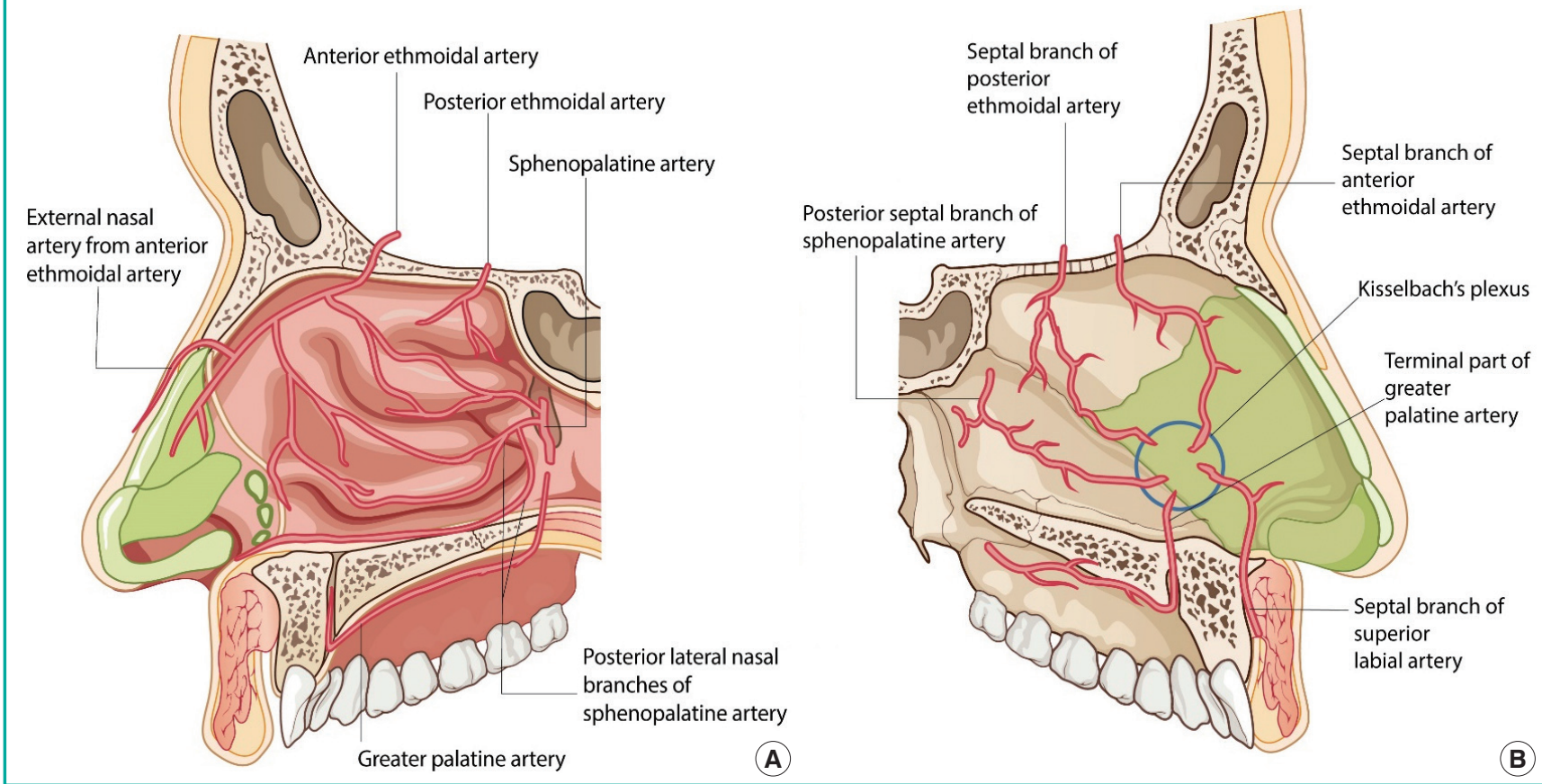

Fig. 11. Intranasal synechia on endoscopy and CT scan

Intranasal synechia in a patient who underwent septoplasty at another clinic. Endoscopic view: right cavity (A) and left cavity (B). Computed tomography (CT) scan: axial view (C) and coronal view (D).
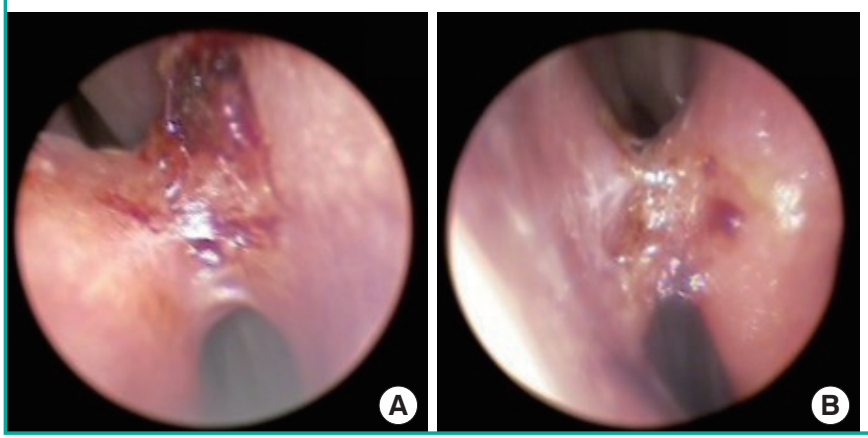

septal cartilage harvesting. Improper dissection increases the risk of complications such as septal hematoma, mucosal thinning, and septal perforation. With the presence of such complications, septal instability may come due to weakened perichondrial support.

Septal perforation is a devastating complication after surgery that may occur when there is trauma to the septal mucosa, and spontaneous healing is rare (Fig. 12). Although a small perforation may not cause profound functional problems, patients may present clinically with a whistling sound when breathing. The severity of symptoms may increase with symptoms ranging

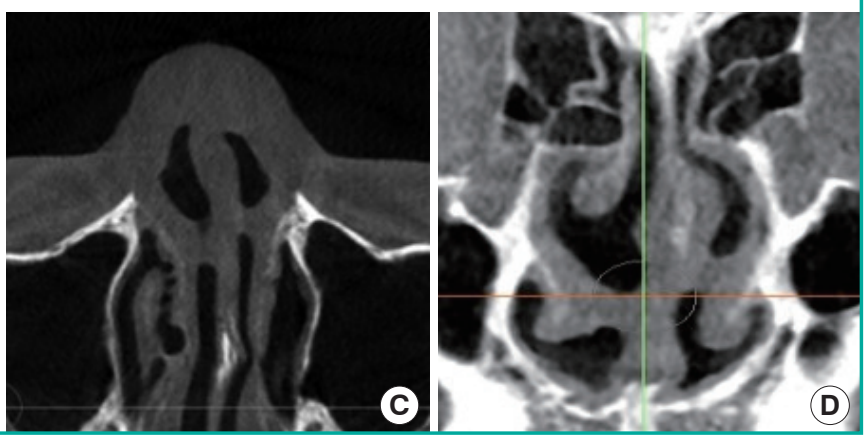

from persistent crust formation, foreign body sensation, and bleeding to respiratory discomfort. Once septal perforation is diagnosed, the patient should receive active clinical follow-up and management. The perichondrial layer strengthens the nasal septal lining and prevents nasal septal perforation by imparting principal biomechanical strength to the septal lining [43].

A recent study by Topal et al. [44] showed that patients with allergic rhinitis had a higher risk of septal perforation. Chronic use of steroids, increased mucosal fragility as a result of chronic inflammation, and the eventual loss of nasal mucosal epithelial integrity were factors that predisposed patients to septal perforation. 
Fig. 12. Septal perforation on endoscopy and CT scan

Septal perforation in a patient who visited the clinic with nasal obstructive symptoms. (A) Endoscopic view. Computed tomography (CT) scan: axial view (B), coronal view (C), and sagittal view (D).
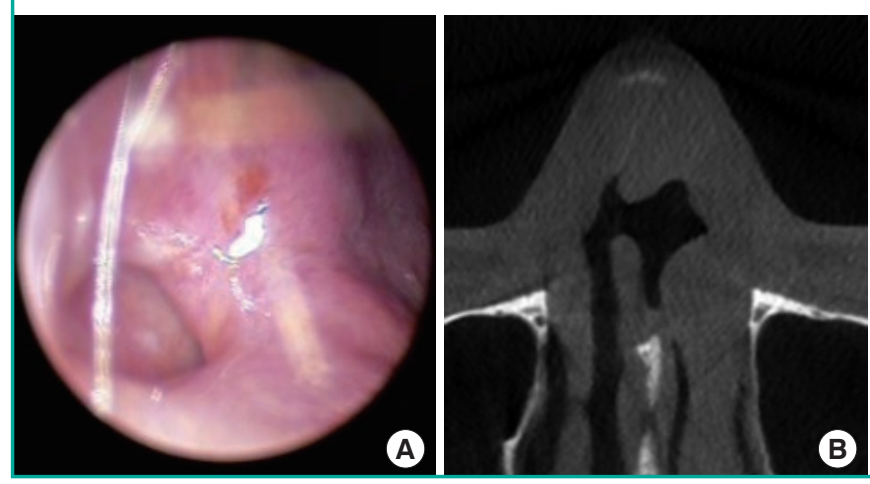

\section{Empty nose syndrome}

Radical turbinectomy is no longer routinely practiced because total inferior turbinectomy may give rise to significant adverse nasal symptoms, including nasal obstruction, nasal dryness, and a sensation of being unable to breathe, as described by Passali et al. [45]. Empty nose syndrome, an iatrogenic disorder, is a rare but devastating complication that arises from the loss of turbinate tissue, since it is difficult to correct or restore the turbinate after it is removed. Therefore, inferior turbinate resection should be performed with extreme caution and mucosa-sparing operations should be advocated to prevent empty nose syndrome $[46,47]$.

\section{CONCLUSIONS}

Correction of nasal deviation is surgically complex, and surgeons should have a profound understanding of the mechanical and physiological changes of structures in the nasal cavity, including the septum and turbinates, for functional improvement and physiological patency. In addition, the aesthetic aspects cannot be neglected during rhinoplasty in patients with deviated nose and septum. Moreover, postoperative examination to prevent and manage possible complications during the surgical management of the septum and turbinates should be emphasized.

\section{NOTES}

\section{Conflict of interest}

No potential conflict of interest relevant to this article was reported.

\section{Author contribution}

Conceptualization: JY Jeong. Formal analysis: TK Kim. Meth-
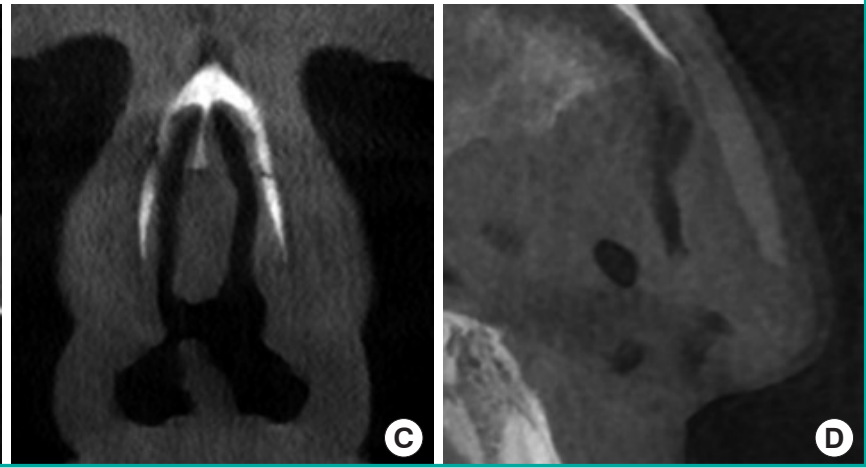

odology: TK Kim. Project administration: TK Kim, JY Jeong. Visualization: JY Jeong. Writing - original draft: TK Kim. Writing - review \& editing: JY Jeong.

\section{ORCID}

Taek Kyun Kim https://orcid.org/0000-0002-3213-9803 Jae Yong Jeong https://orcid.org/0000-0001-5654-4443

\section{REFERENCES}

1. Jeong JY, Kim TK. Rebuilding nose: rhinoplasty for Asians. 1st ed. Uijeongbu: Medic Medicine; 2018.

2. Courtiss EH, Gargan TJ, Courtiss GB. Nasal physiology. Ann Plast Surg 1984;13:214-23.

3. Geurkink N. Nasal anatomy, physiology, and function. J Allergy Clin Immunol 1983;72:123-8.

4. Holt GR. Biomechanics of nasal septal trauma. Otolaryngol Clin North Am 1999;32:615-9.

5. Kim TK, Jeong JY. Surgical anatomy for Asian rhinoplasty: Part II. Arch Craniofac Surg 2020;21:143-55.

6. Jeong JY. Obtaining maximal stability with a septal extension technique in East Asian rhinoplasty. Arch Plast Surg 2014; 41:19-28.

7. Muir $\mathrm{H}$. The chondrocyte, architect of cartilage: biomechanics, structure, function and molecular biology of cartilage matrix macromolecules. Bioessays 1995;17:1039-48.

8. Gorur K, Polat G, Ozcan C, et al. The role of apoptosis in traumatic versus nontraumatic nasal septal cartilage. Plast Reconstr Surg 2007;119:1773-8.

9. Wexler DB, Davidson TM. The nasal valve: a review of the anatomy, imaging, and physiology. Am J Rhinol 2004;18: 143-50.

10. Hadar T, Ophir D, Yaniv E, et al. Inferior turbinate arterial supply: histologic analysis and clinical implications. J Oto- 
laryngol 2005;34:46-50.

11. Berger G, Hammel I, Berger R, et al. Histopathology of the inferior turbinate with compensatory hypertrophy in patients with deviated nasal septum. Laryngoscope 2000;110: 2100-5.

12. Uzun L, Savranlar A, Beder LB, et al. Enlargement of the bone component in different parts of compensatorily hypertrophied inferior turbinate. Am J Rhinol 2004;18:405-10.

13. Akoglu E, Karazincir S, Balci A, et al. Evaluation of the turbinate hypertrophy by computed tomography in patients with deviated nasal septum. Otolaryngol Head Neck Surg 2007; 136:380-4.

14. Chand M, Toriumi D. Nasal physiology and management of the nasal airway. In: Gunter JP, Rohrich RJ, Adams WP, editors. Dallas rhinoplasty: nasal surgery by the masters. St. Louis: Quality Medical Publishing, Inc.; 2002. p. 643-61.

15. Howard BK, Rohrich RJ. Understanding the nasal airway: principles and practice. Plast Reconstr Surg 2002;109:112846.

16. Dinc ME, Bayar Muluk N, Vonakis BM. Physiology of the nose and paranasal sinuses. In: Cingi C, Bayar Muluk N, editors. All around the nose. Cham: Springer; 2002. p. 57-63.

17. Jang YJ, Myong NH, Park KH, et al. Mucociliary transport and histologic characteristics of the mucosa of deviated nasal septum. Arch Otolaryngol Head Neck Surg 2002;128: 421-4.

18. Kamani T, Yilmaz T, Surucu S, et al. Histopathological changes in nasal mucosa with nasal septum deviation. Eur Arch Otorhinolaryngol 2014;271:2969-74.

19. Kumar L, Belaldavar BP, Bannur H. Influence of deviated nasal septum on nasal epithelium: an analysis. Head Neck Pathol 2017;11:501-5.

20. Stannard W, O'Callaghan C. Ciliary function and the role of cilia in clearance. J Aerosol Med 2006;19:110-5.

21. Cohen NA. Sinonasal mucociliary clearance in health and disease. Ann Otol Rhinol Laryngol Suppl 2006;196:20-6.

22. Millas I, Liquidato BM, Dolci JE, et al. Histological analysis of the distribution pattern of glandular tissue in normal inferior nasal turbinates. Braz J Otorhinolaryngol 2009; 75:50710.

23. Berger G, Finkelstein Y, Ophir D, et al. Old and new aspects of middle turbinate histopathology. Otolaryngol Head Neck Surg 2009; 140:48-54.

24. Berger G, Gass S, Ophir D. The histopathology of the hypertrophic inferior turbinate. Arch Otolaryngol Head Neck Surg 2006; 132:588-94.

25. Berger G, Balum-Azim M, Ophir D. The normal inferior turbinate: histomorphometric analysis and clinical implica- tions. Laryngoscope 2003;113:1192-8.

26. Chhabra N, Houser SM. The surgical management of allergic rhinitis. Otolaryngol Clin North Am 2011;44:779-95.

27. Eccles R. A role for the nasal cycle in respiratory defence. Eur Respir J 1996;9:371-6.

28. Kumaran EM. Alteration in nasal cycle rhythm as an index of the diseased condition. In: Graz DC, editor. Pathophysiology: altered physiological states. London: Intechopen; 2018. https://doi.org/10.5772/intechopen.70599.

29. Thulesius HL, Cervin A, Jessen M. The importance of side difference in nasal obstruction and rhinomanometry: a retrospective correlation of symptoms and rhinomanometry in 1000 patients. Clin Otolaryngol 2012;37:17-22.

30. Kern EB, Arbour P. The phenomenon of paradoxical nasal obstruction. Arch Otolaryngol 1976;102:669-71.

31. Kim HY, Dhong HJ, Hong SD, et al. Paradoxical nasal obstruction: analysis of characteristics using acoustic rhinometry. Am J Rhinol 2007;21:408-11.

32. Downs BW. The inferior turbinate in rhinoplasty. Facial Plast Surg Clin North Am 2017;25:171-7.

33. Gil Z, Margalit N. Anteriorly based inferior turbinate flap for endoscopic skull base reconstruction. Otolaryngol Head Neck Surg 2012;146:842-7.

34. Cannon CR. Endoscopic management of concha bullosa. Otolaryngol Head Neck Surg 1994;110:449-54.

35. Becker DG, Ransom E, Guy C, et al. Surgical treatment of nasal obstruction in rhinoplasty. Aesthet Surg J 2010;30: 347-78.

36. Ahmed EA, Hanci D, Ustun O, et al. Surgical techniques for the treatment of concha bullosa: a systematic review. Otolaryngol Open J 2018;4:9-14.

37. MacArthur FJ, McGarry GW. The arterial supply of the nasal cavity. Eur Arch Otorhinolaryngol 2017;274:809-15.

38. Chiu T, Dunn JS. An anatomical study of the arteries of the anterior nasal septum. Otolaryngol Head Neck Surg 2006; 134:33-6.

39. Padgham N, Vaughan-Jones R. Cadaver studies of the anatomy of arterial supply to the inferior turbinates. J R Soc Med 1991;84:728-30.

40. Shone GR, Clegg RT. Nasal adhesions. J Laryngol Otol 1987; 101:555-7.

41. White A, Murray JA. Intranasal adhesion formation following surgery for chronic nasal obstruction. Clin Otolaryngol Allied Sci 1988;13:139-43.

42. Jackson LE, Koch RJ. Controversies in the management of inferior turbinate hypertrophy: a comprehensive review. Plast Reconstr Surg 1999; 103:300-12.

43. Kim DW, Egan KK, O’Grady K, et al. Biomechanical strength 
of human nasal septal lining: comparison of the constituent layers. Laryngoscope 2005; 115:1451-3.

44. Topal O, Celik SB, Erbek S, et al. Risk of nasal septal perforation following septoplasty in patients with allergic rhinitis. Eur Arch Otorhinolaryngol 2011;268:231-3.

45. Passali D, Lauriello M, Anselmi M, et al. Treatment of hypertrophy of the inferior turbinate: long-term results in 382 patients randomly assigned to therapy. Ann Otol Rhinol Laryngol 1999; 108:569-75.

46. Houser SM. Surgical treatment for empty nose syndrome. Arch Otolaryngol Head Neck Surg 2007; 133:858-63.

47. Chhabra N, Houser SM. The diagnosis and management of empty nose syndrome. Otolaryngol Clin North Am 2009; 42:311-30. 